\title{
Contemporary Trends in Novel Ophthalmic Drug Delivery System: An Overview
}

\author{
Safila Naveed ${ }^{*}$, Sidra Farooq ${ }^{2}$, Syeda Sarah Abbas ${ }^{1,2}$, Syed Hameez Jawed ${ }^{2}$, \\ Fatima Qamar', Mirza Yasir Hussain², Iqra Ali ${ }^{3}$ \\ ${ }^{1}$ Faculty of Pharmacy, Jinnah University for Women, Karachi, Pakistan \\ ${ }^{2}$ Department of Pharmaceutics, Faculty of Pharmacy, University of Karachi, Karachi, Pakistan \\ ${ }^{3}$ Dow College of Pharmacy, Karachi, Pakistan \\ Email: “drsafila@gmail.com, sidra.farooq@live.com, hameez.jawed89@gmail.com, \\ syedasarahabbas@yahoo.com, fatimamudassar2009@hotmail.com
}

Received 12 April 2015; accepted 28 April 2015; published 8 May 2015

Copyright (C) 2015 by authors and OALib.

This work is licensed under the Creative Commons Attribution International License (CC BY). http://creativecommons.org/licenses/by/4.0/

(c) (i) Open Access

\begin{abstract}
One of the most challenging tasks faced by the pharmaceutical researchers is the ophthalmic drug delivery. Their aim is to obtain and maintain a therapeutic level at the site of action for prolonged period of time. Therefore, to sustain drug levels at the target site for a sufficient time, novel drug delivery techniques should be developed. Ophthalmic drug delivery has proved significant advancement for future point of view. This article evaluates a variety of novel systems for ophthalmic drug delivery.
\end{abstract}

\section{Keywords}

Ophthalmic Drug Delivery, Novel Drug Delivery Techniques, Pharmaceutical Researchers, Therapeutic Level

Subject Areas: Pharmacology, Public Health

\section{Introduction}

Novel drug delivery systems are new in the market and are the modifications of previous ones in terms of unique delivery systems or unique devices, which are to be used before during or after administration. The existing therapies are diminishing because of the development of new technologies. New drug delivery systems increase the amount and persistence of a drug in the vicinity of target cells and minimize the drug exposure of non target cells, in consequence promoting the therapeutic effects of a drug and reducing its toxic effects [1]. One of the most confronting routes of delivery for the pharmaceutical researchers is ophthalmic drug delivery [2]. The

"Corresponding author.

How to cite this paper: Naveed, S., Farooq, S., Abbas, S.S., Jawed, S.H., Qamar, F., Hussain, M.Y. and Ali, I. (2015) Contemporary Trends in Novel Ophthalmic Drug Delivery System: An Overview. Open Access Library Journal, 2: e1497.

http://dx.doi.org/10.4236/oalib.1101497 
conventional delivery systems like suspensions, solutionss and ointments have poor ocular bioavailability, i.e. less than $1 \%$, because of various factors which cause fast yield, less absorption \& short residence time in the cul-de-sac and relatively impermeable drugs [3].

The administered dose up to $80 \%$ may be lost by tears and nasolachrymal drainage within 5 minutes of administration. Formulations that may increase the contact period of drug with corneal exterior may use to extend period of therapy and this is achieved by the use of viscosity enhancers, by means of ophthalmic solutions in which drug dissolve slowly or by the use of ophthalmic inserts [1]. Ideality of ophthalmic drug delivery is that it sustains the drug release and provides longer contact with the front of the eye [4]. Novel ophthalmic drug delivery endeavor is to improve drug bioavailability by facilitating the transcorneal drug penetration or/and to ensure a prolonged retention time of the medication in the eye [5]. The topical ocular drug delivery has been improved from eye drops to ophthalmic iontophoresis, in situ gels, dendrimers, ocular inserts mucoadhesive polymers, penetration enhancers, mucoadhesive polymers, hydrogels and targeted drug delivery systems [6]. Most frequently available ophthalmic preparations are eye drops and ointments. Nevertheless these preparations when instilled into the cul-de-sac are rapidly drained away from the ocular cavity due to tear flow and lachrymal nasal drainage. Only a minute amount is available for its therapeutic effect ensuing in frequent dosing. Thus, to overcome these troubles, newer pharmaceutical ophthalmic formulations such as in situ gel, nanoparticle, liposome, nanosuspension, microemulsion, intophoresis and ocular inserts have been developed in last three decades to amplify the bioavailability of the drug as a sustained and controlled approach [7].

\section{Objective}

The purpose of this paper is to briefly appraise the novel techniques for ophthalmic drug delivery so that the pharmaceutical researchers get the concept of the latest trends regarding this aspect.

\section{Ophthalmic Inserts}

The solid devices that are placed in the conjunctival sac and provide slow drug delivery are called ophthalmic inserts [5]. Figure 1 shows ophthalmic inserts based upon their solubility behavior. Figure 2 shows non erodible insert and erodible insert.

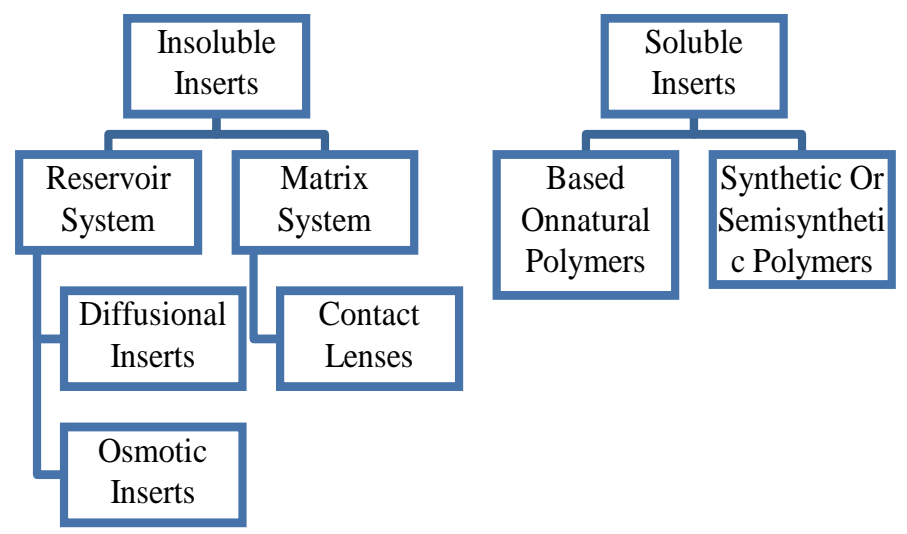

Figure 1. Categorization of ophthalmic inserts based upon their solubility behavior [8].

\begin{tabular}{|c|l|}
\hline Non Erodible Insert & Erodible Insert \\
\hline Ocular Insert & Sodi \\
\hline Hydrogel & Collagen Shield \\
Contact Lens & Minidisc OTC \\
& Ocufit SR \\
\hline
\end{tabular}

Figure 2. Non erodible insert and erodible insert [9]. 


\subsection{Insoluble Ocular Inserts:}

\subsubsection{Reservoir Systems}

The drug is released either by osmosis or diffusion by the reservoir systems which contain a liquid, gel, colloid, semisolid, carrier containing drug or a solid matrix. The carriers are prepared of polymers such as hydrophilic, hydrophobic, organic, natural or synthetic.

\section{$>$ Diffusional Insert or Ocusert:}

Diffusional insert is based on porous membrane and the drug release is based on mechanism of diffusional release.

\section{> Osmotic Insert:}

The osmotic insert comprise of a peripheral part which surrounds the central part.

\subsubsection{Matrix Systems}

They are represented by contact lenses mainly which are composed of hydrophilic or hydrophobic polymers that are covalently cross linked and form a three dimentional matrix network which retains water, solid components or aqueous drug solution [8].

\section{$>$ Contact Lenses:}

Absorption by contact lenses of water soluble drugs in drug solutions is achieved by soaking and is used to achieve sustain drug release and for this purpose hydrophilic contact lenses are used [4]. Figure 3 shows types of lense.

Soft hydrogel contact lenses were developed to achieve prolonged drug release [8].

\subsection{Types of Polymeric Hydrogels}

In the veterinary patients, treatment of ocular surface and anterior segment can be achieved by specialized drug eluting contact lenses, which have proved to be beneficial [11]. Figure 4 shows polymeric hydrogels.

\section{Soluble Ocular Inserts:}

They don't need to remove from the site of application because they offer the advantage of solubility, therefore they limit the intervention to insertion only [8]. Figure 5 and Table 1 show ophthalmic inserts.

\section{Advantages of Ophthalmic Inserts:}

- They provide increased contact time, better bioavailability and prolonged drug release.

- They provide better efficacy as well as administration of exact dose in the eye.

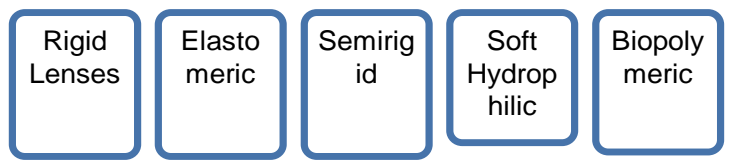

Figure 3. Subdivision of contact lenses [8].

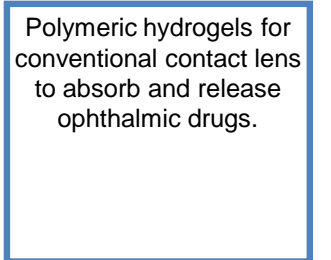

Ion ligand-containing polymeric hydrogels
Polymeric hydrogels for piggyback contact lens combining with a drug plate or drug solution

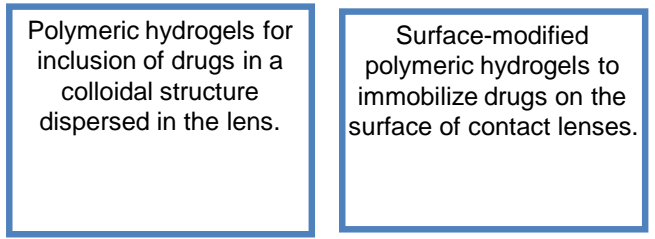

Molecularly imprinted polymeric hydrogels.

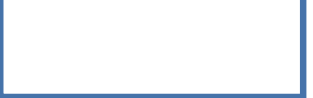

Figure 4. Polymeric hydrogels for novel contact lens-based ophthalmic drug delivery systems [10]. 


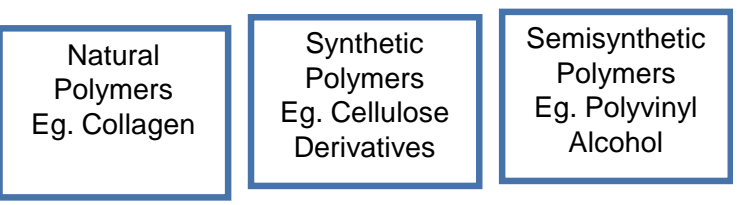

Figure 5. Classification of soluble ophthalmic inserts [8].

Table 1. Types of ophthalmic inserts.

\begin{tabular}{|c|c|c|}
\hline Reference & Type & Description \\
\hline$[9][12]$ & SODI (soluble & They are oval, sterile, thin films that weigh 15 - $16 \mathrm{mg}$. \\
\hline$[13]$ & $\begin{array}{l}\text { ophthalmic } \\
\text { drug insert) }\end{array}$ & $\begin{array}{l}\text { It is like a small wafer which softens on insertion. It comprises of soluble } \\
\text { copolymers which consist of acryl amide, } \mathrm{N} \text {-vinyl pyrolidone and ethyl acrylate. }\end{array}$ \\
\hline$[12]$ & $\begin{array}{c}\text { NODS (New } \\
\text { ophthalmic } \\
\text { delivery system) }\end{array}$ & $\begin{array}{l}\text { The drugs are administered to the eye in the form of film which is loaded with water } \\
\text { soluble drug. It is preservative free and it provides accurate and reproducible dosing, } \\
\text { water soluble polyvinyl alcohol film incorporates the drug. }\end{array}$ \\
\hline$[8]$ & Collagen shields & It is erodible disc which consist of scleral collagen that is cross linked porcine. \\
\hline$[4]$ & $\begin{array}{l}\text { Artificial } \\
\text { tear insert }\end{array}$ & $\begin{array}{l}\text { It is used for the treatment of dry eye disorder, also termed lacrisert. } \\
\text { It's a rod shaped pellet that is designed as artificial tear and provides sustained release. } \\
\text { It is made up of hydroxy propyl cellulose and doesnot contain preservative. }\end{array}$ \\
\hline$[8]$ & Ocusert & $\begin{array}{l}\text { Insoluble flat flexible device consisting of } 2 \text { layers in which a reservoir is enclosed. } \\
\text { Commercially, it is used to deliver pilocarpine for seven days. }\end{array}$ \\
\hline$[12]$ & $\begin{array}{l}\text { BODI (Bio } \\
\text { adhesive ophthalmic } \\
\text { drug inserts) }\end{array}$ & $\begin{array}{l}\text { They belong to soluble inserts group which are made up of } \\
\text { synthetic and semisynthetic polymers. }\end{array}$ \\
\hline [9] & $\begin{array}{c}\text { Hydrogel } \\
\text { contact lenses }\end{array}$ & $\begin{array}{l}\text { Their water absorbance is upto } 80 \% \text { which depends on their composition, } \\
\text { amount of hydroxyl groups and degree of cross linking. }\end{array}$ \\
\hline$[8]$ & $\begin{array}{l}\text { Minidisc OTC } \\
\text { (ocular therapeutic }\end{array}$ & $\begin{array}{l}\text { It is a monolytic device which is shaped like a miniature polymeric contact lens. } \\
\text { Its diameter is } 4-5 \mathrm{~mm} \text {. with a convex and concave face. } \\
\text { The concave face be conventional to the eye sclera. }\end{array}$ \\
\hline$[9]$ & system) & $\begin{array}{l}\text { The OTS offer extended release of water soluble and water insoluble drugs } \\
\text { because it may be hydrophilic or hydrophobic. }\end{array}$ \\
\hline$[14]$ & $\begin{array}{l}\text { Non biodegradable } \\
\text { implants }\end{array}$ & $\begin{array}{l}\text { It has non biodegradable polymers coating. It is reservoir type and exhibits the most } \\
\text { long lasting release profile of drug because it reserves a large drug amount. }\end{array}$ \\
\hline$[11]$ & & They provide sustained drug release after being placed in the lower conjunctival sac. \\
\hline$[14]$ & $\begin{array}{l}\text { Biodegradable } \\
\text { implants }\end{array}$ & $\begin{array}{l}\text { Processing of this can be into nanoparticles, rods, discs or tablets and many } \\
\text { varieties of configurations. As an outcome they stabilize the drug release profile, } \\
\text { as well as cut down the drug release extent because the drug content is limited. }\end{array}$ \\
\hline$[8]$ & $\begin{array}{l}\text { Bio erodible } \\
\text { ocular inserts }\end{array}$ & $\begin{array}{l}\text { These comprise of bioerodible polymers such as derivatives of cross linked gelatin } \\
\text { and polyester which undergo dissolution and chemical bonds hydrolysis. }\end{array}$ \\
\hline$[8]$ & Ocufit SR & $\begin{array}{l}\text { It is a rod shaped device made up of silicone elastomer } \\
\text { and provides sustained drug release. }\end{array}$ \\
\hline$[15]$ & Non erodible & $\begin{array}{l}\text { They are non biodegradable. They have superior reliability since they } \\
\text { are easily detected when expelled. They have better drug release kinetics. }\end{array}$ \\
\hline [9] & inserts & $\begin{array}{l}\text { Non erodible ocular inserts have dispersed drug so the major mechanism } \\
\text { of absorption is passive diffusion. }\end{array}$ \\
\hline$[8]$ & $\begin{array}{l}\text { Erodible } \\
\text { inserts }\end{array}$ & $\begin{array}{l}\text { The polymer is fabricated as hydrophobic but is biodegradable. } \\
\text { Drug is released as a result of surface erosion of the insert. } \\
\text { After intended drug delivery episode, they don't require exclusion. }\end{array}$ \\
\hline
\end{tabular}

- They are sterile, stable without preservatives and provide reduced systemic and adverse effects with increased shelf life due to absence of water.

- They are advantageous on account of their compliance, ease of handling and insertion, lack of explosion, reproducibility of release kinetics as well as non interference with vision and oxygen permeability [8]. 
- Examples of implantable systems that deliver sustained drug release to the eyes include membrane controlled, implantable infusion and implantable silicon devices and systems. Silicon rubber balloon with antineoplastic agent is evaluated as an example of implantables for management of ocular cancer [16].

- Non biodegradable implants and inserts are the clinically successful cases that have been recently developed in intraocular delivery systems to enable effective ocular drug delivery [17].

- A new hope for the fungal deratitis patients is the concept of intracorneal insert [13].

Disadvantages of Ophthalmic Inserts:

- Immediate loss of the insert or the device may be dislocated in front of the pupil.

- If the insert twists, it forms a figure eight, therefore the delivery rate diminishes and a leakage may occur [8]. Recent Studies:

Malaekeh-Nikouei et al. prepared a series of imprinted and non imprinted hydrogels using 2-hydroxy ethyl methacrylate (HEMA) as a backbone monomer, ethylene glycol dimethacrylate (EGDMA) as a cross linker monomer, methacrylic acid (MAA) as a functional monomer and dorzolamide (DZD) as a template molecule. The authors concluded that the use of suitable co-monomer and applying a molecular imprinting technique had important influence on loading and releasing properties of hydrogels [17].

Peng et al. compared the efficacy of timolol delivered via contact lenses to eye drops in beagle dogs that suffered from spontaneous glaucoma. Experiments were conducted with NIGHT AND DAY silicone hydrogel contact lenses and NIGHT AND DAY loaded with vitamin E, which was included in the lens to extend the drug release duration. The authors concluded that the ophthalmic drug delivery through contact lens increased bioavailability and reduced systemic drug uptake [18].

Sindhumol et al. formulated sodium cromoglycate ophthalmic inserts using hydroxy propyl methyl cellulose and gelatin as polymers by solvent casting method with aim of compliance and greater therapeutic efficacy. The prepared ocular inserts were then evaluated. In vitro release studies of formulated ocuserts were performed. The authors concluded that the formulation of ophthalmic inserts containing sodium cromoglycate and HPMC (1:2) seemed to be promising [19].

Gilhotra et al. formulated ophthalmic insert of brimonidine tartrate using PVA, chitosan, HPMC and sodium alginate via solvent casting method. The prepared inserts were then estimated. The authors accomplished that the chitosan based brimonidine ocular insert could be a potential vehicle to enhance ocular bioavailability and patient compliance [20].

Shanmugam et al. prepared inserts containing acyclovir by using solvent casting method. Rate controlling membrane and drug reservoir were prepared using different hydrophilic and hydrophobic polymers respectively with polyethylene glycol 400 as plasticizer. The prepared inserts were evaluated. The authors concluded that the developed formulation was stable, sterile and non irritant [21].

Rajasekaran et al. studied that ocular drug delivery system for natamycin, a polyene antibiotic was highly useful for the treatment of conjunctivitis and keratitis. They prepared ocuserts using different polymers at various proportion and permutation. They evaluated prepared ocuserts. The authors concluded that the ocuserts of natamycin were capable of exhibiting controlled drug release with ideal sterility and stability [2].

Molokhia et al. devoloped a novel intraocular implant for drug delivery. The capsule drug ring was a reservoir introduced in the lens capsule during cataract surgery refillable and capable of delivering multiple drugs and avastin was the drug of interest in this study. Prototypes were manufactured. The device showed near zero order release kinetics and the authors investigated avastin stability with accelerated temperature studies [22].

Ramkanth et al. prepared diclofenac sodium ocuserts by using different polymers such as HPMC, HPC, MC and EC at various concentrations and combinations using dibutyl phthalate as plasticizer. They prepared ocuserts by solvent casting technique. The prepared ocuserts were evaluated. The authors concluded that the formulation had achieved the targets of present study as prolonged zero order release increase in contact time and reduction in frequency of administration and thus improved patient compliance [23].

\section{Colloidal Carriers}

They are successful drug carriers for ophthalmic applications. The significant absorption of drug in comparison with eye drops owe to the slower elimination rate of particles in the ocular region. Smaller particles have better tolerance by the patients than larger particles; therefore nanoparticles may represent very promising ophthalmic delivery systems providing prolonged action [24]. Colloidal carriers may emerge as an alternative and substantially improve the present therapy, subsequent their periocular administration [25] (Table 2). 
Table 2. Types of colloidal carriers.

\begin{tabular}{|c|c|c|}
\hline Reference & Colloidal Carriers & Description \\
\hline$[9]$ & Liposomes: & $\begin{array}{l}\text { The amount of concentric alternating layers of phospholipids } \\
\text { and aqueous phases decides that the liposome is either unilamellar or multilamellar. }\end{array}$ \\
\hline$[25]$ & Nano Particles & $\begin{array}{l}\text { They have diameter of less than } 1 \text { micrometer consisting of various } \\
\text { biodegradable polymers or non-biodegradable metals, lipids or phospholipids. } \\
\text { Depending upon whether the drug has been coated with a polymeric material } \\
\text { or has been uniformly dispersed, they can be classified as nanocapsules or nanospheres. }\end{array}$ \\
\hline$[26]$ & $\begin{array}{l}\text { Bioadhesive } \\
\text { Nanopolymers }\end{array}$ & $\begin{array}{c}\text { The interaction of bioadhesive polymer chains with mucin and the potential entrapment } \\
\text { of particles in the mucus layer of ocular surface are the basis of the development } \\
\text { of particulate systems for ophthalmic drug delivery. }\end{array}$ \\
\hline$[25]$ & Microparticulates & $\begin{array}{l}\text { Micron sized polymeric particles that contain the drug and are suspended } \\
\text { in a liquid medium, or the drug can be dispersed in a polymer backbone physically. }\end{array}$ \\
\hline$[27]$ & & $\begin{array}{c}\text { They have } 20 \text { - } 200 \mathrm{~nm} \text { droplet size usually, and are isotropic, transparent, translucent, } \\
\text { thermodynamically stable system of oil, surfactant and water. }\end{array}$ \\
\hline [5] & Microemulsions & $\begin{array}{c}\text { They appear as clear transparent dispersions and comprise of larger swollen micelles } \\
\text { that contain the internal phase. }\end{array}$ \\
\hline$[28]$ & & Eg. Polyanhydride microspheres, polyadipic acid. \\
\hline$[25]$ & Niosomes & $\begin{array}{l}\text { The power of irritation of surfactants decrases in the following order: } \\
\text { cationic }>\text { anionic }>\text { ampholytic }>\text { nonionic, therefore the nonionic surfactants are preferred. } \\
\text { For mutually hydrophilic and lipophilic drugs, niosomes are a suitable delivery system. }\end{array}$ \\
\hline$[29]$ & Nanocrystals & The mean diameter of pure solid drug nanocrystals is below 1000 nanometer. \\
\hline [25] & Nanosuspensions & Nanosuspensions are inert in nature and usually consist of colloidal carriers like polymeric resins. \\
\hline$[30]$ & Dendrimers & $\begin{array}{l}\text { Dendrimers are macromolecules or nanosized, radially symmetric molecules having } \\
\text { repeated tree like arms or branches, having well defined homogenous and monodisperse } \\
\text { structure and they can resolve the increasing challenges of newly developed } \\
\text { drugs such as bioavalability, permeability and poor solubility. }\end{array}$ \\
\hline
\end{tabular}

\section{Advantages:}

- Liposomes are biocompatible, stable and biodegradable liquid preparations; therefore they improve the bioavailability of ophthalmic drugs after topical administration [9].

- Nanoparticles after being topically administered are retained in the cul-de-sac to provide sustained drug release and prolonged therapeutic activity because the entrapped drug is released at appropriate rate from the particles. Nanosuspensions are nonirritant and help in drug solubility enhancement and bioavailability.

- Microparticulates can be administered topically as an eye drop thus providing better patient acceptability [25].

- By the use of nanoparticles, drug surface area is increased per mole of drug compound which increases tissue exposure and absorption [11].

Disadvantages:

- Major issues for colloidal carriers involve dispersed phase percentage/problem of entrapment coefficient, i.e. amount of active ingredient present in a drop of the final product.

- Antimicrobial preservation, stability and shelf life.

- Tolerance of surfactants that are used.

- Bulk manufacture of sterile preparations [12].

- Make use of nanoparticles, drug surface area is increased per mole of drug compound which increases tissue exposure and absorption [11].

\section{Recent Studies:}

Sabitha et al. developed and evaluated moxifloxacin containing nanoparticles as potential ophthalmic drug delivery system. Nanoparticles were prepared and characterised. The in vitro release profile of moxifloxacin from the nanoparticles and the dispersion was observed. The authors concluded that moxifloxacin loaded chitosan nanoparticles appeared promising for effective management of ocular conjunctivitis infections [3].

Han et al. developed a cubosomes based novel vehicle as an ophthalmic drug delivery system for flurbiprofen 
to ease ocular aggravation and increase bioavailability. They prepared cubosomes loaded with flurbiprofen via homogenization through hot and high pressure. The authors concluded that cubosomes based low irritant novel vehicle might be a capable technique for efficient ocular delivery [31].

\section{Iontophoresis}

The method which is minimally invasive and has ability to propel charge compounds, i.e. low molecular weight drugs, high molecular weight biological proteins (less than $14 \mathrm{kDa}$ ) into ocular tissues is iontophoresis [11]. A mild electric current is required to enhance ioniqed drug penetration into the tissues. E.g. OcuPhor system designed for transscleral iontophoresis is designed with dispersive electrode, an applicator and a dose controller.

\section{Advantages:}

- Iontophoresis drug delivery can overcome the potential side effects caused by intraocular injections and implants [25].

- Fungal keratitis, uveitis, retinitis, retinoblastoma, proliferative vitreal retinopathy and various retinal degenerations are the diseases that may benefit by ocular iontophoresis [11].

\section{Disadvantages:}

- If improperly used, there is a possibility of burns and pains due to excessive current density, therefore iontophoretic delivery is limited clinically for brief drug delivery period applications.

- For iontophoretic delivery, ionic form of drug in sufficient concentration is necessary. Due to high molecular weight, i.e. 8000 - 12,000, tentative delivery rate results [32].

\section{In Situ Gels}

In situ gels change in certain physicochemical parameters like temperature, ionic concentration or $\mathrm{pH}$ thus reveal transition of sol to gel phase on the ocular surface [33].

Various approaches of in situ gelation (Figure 6):

Advantages:

- Patient compliance, reducing frequency of administration and easy to instill.

- High-quality stability along with biocompatibility uniqueness [35].

- The drug remains for longer period at the desired site due to increased contact time of the drug to the tissue [24].

- Less blurred vision than ointments (Less blurred vision as compared to ointment) [36].

- Endow with sustained drug release owing to amplified residence time [37].

\section{Disadvantages:}

The gels have open pore structure that does not extend the duration of drug beyond a few hours because gels are water predominantly [11].

\section{Recent Studies:}

Vodithala et al. formulated and evaluated the in situ ocular gelling systems (ion activated gelling systems) of

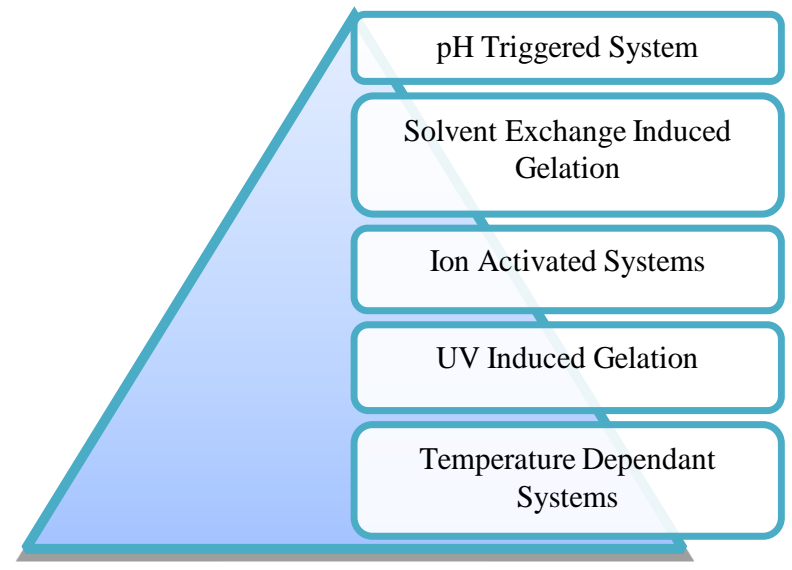

Figure 6. Kinds of system in in situ gelation [34]. 
ketorolac tromethamine. These gelling systems engage the use of gelrite as polymer. The formulations were evaluated and ex vivo corneal permeation studies carried out. The authors found that the developed formulation showed sustained release of drug for up to $6 \mathrm{~h}$ and concluded that the formulation was found to be non irritating with no ocular damage [33].

Hiremath et al. prepared and evaluated ophthalmic drug delivery system of linezolid based on novel in situ gum. The authors used hydroxypropyl guar and xanthum as gum with the amalgamation of viscosity enhancing agents like carbopol, hydroxyethyl cellulose and sodium alginate. Appropriate dilutions of buffering agents were used for $\mathrm{pH}$ adjustment to 7.4 and the evaluation and sterilization of the formulations was done. The authors found that the formulations were soothing with no ocular harm or unusual clinical indication to the iris, cornea or conjunctiva and concluded that gums holding in situ gelling systems may be a beneficial substitute to the conventional systems [37].

Varshoaz et al. increased the low bioavailability and short ocular residence time of ciprofloxacin eye drops. They prepared aqueous solutions of drug in chitosan/pluronic (poloxamer). Mixtures of solutions of pluronic (10\% - $25 \% \mathrm{w} / \mathrm{w})$ with chitosan $(0.1 \%-0.3 \% \mathrm{w} / \mathrm{w})$ of different molecular weights $(\mathrm{Mw})$ were prepared. Ciprofloxacin release was determined. The rheological behavior, phase change temperature (PCT) and antimicrobial effect of the solutions was studied. The authors found that this in situ gel released the drug by a Higuchi model and Fickian mechanism, it was liquid in non-physiologic conditions and transferred to the gel form upon physiologic conditions and they concluded that the PCT of this in situ gel did not change upon dilution and the zone of inhibition of the growth of both studied bacteria was significantly greater for it than the marketed eye drop of ciprofloxacin [38].

\section{Prodrugs}

Prodrugs are chemically or enzymatically liable simple derivatives of drugs, which as a result of hydrolysis in the eye are converted to their active parent. Functional groups such as alcohol, phenol, carboxylic acid and amine are present in most ophthalmic drugs and lend to derivatization. By changing the physicochemical belongings of drugs, the chemical structures are adapted.

\section{Advantages:}

- Prodrug technique improves corneal permeability of drugs.

- Pharmaceutical formulation problems such as poor solubility and stability are also solved [9]. Disadvantages:

- After it reaches the site of action, the metabolism of the prodrugs is not controlled and the toxicity concerns can't be ruled out completely.

- As an outcome of reactive intermediate, the adverse drug reaction can possibly occur [39].

“Ophthalmic Drug Delivery Systems for the Management of Retinal Diseases: Clinical Applications:

Combined Anterior and Posterior Segment Diseases”

Endophthalmitis, uveitis, and glaucoma are common combined anterior and posterior segment diseases, but each presents a different unmet need. For endophthalmitis, the unmet need is prevention. When prevention fails, treatment is the most effectively performed with prompt intravitreal and subconjunctival antibiotics, with or without vitrectomy and systemic antibiotics. For uveitis, high-quality short-term control of the disease can be obtained with topical, periocular, or systemic anti-inflammatory or immunosuppressive drugs (e.g., corticosteroids). The major unmet need involves the treatment of chronic or recurrent uveitic disease, because long-term treatment with these agents commonly results in toxicity and complications due to cumulative dose-related side effects, such as cataract and glaucoma. Finally, for glaucoma, although fair to adequate control of intraocular pressure can be obtained with topical drugs and various anterior segment procedures and surgeries, a treatment for optic nerve or ganglion cell neurodegeneration is still largely unavailable [40].

\section{Posterior Segment Diseases}

Concerning strictly posterior segment diseases, the two major blinding diseases in the United States are diabetic retinopathy (DR) and age-related macular degeneration (AMD). DR is the main cause of irreversible blindness in adults aged 20 to 65 years old, with incidence rates of 56\% for nonproliferative DR and $29 \%$ for proliferative DR. Macular edema (ME) occurs in approximately $10 \%$ of diabetics. AMD is the main cause of irreversible blindness in adults older than 65 years old. The prevalence of all forms of AMD in the 65- to 74-year-old age group is $20 \%$, and it is closer to $35 \%$ in older age groups [41]. 


\section{Conclusion}

In this review, we have discussed some of the novel techniques for ophthalmic drug delivery. In the novel delivery system, various approaches and carriers are used like in situ gelling, ophthalmic inserts, nanoparticles, liposomal formulation, dendrimers, prodrugs and ocular iontophoresis. Conventional ophthalmic formulations like eyedrops have less retention time in ocular cavity and less than $10 \%$ of the administered dose could cross the membrane. Therefore, to satisfy the need, novel delivery systems have been developed to improve the delivery of a therapeutic agent.

\section{References}

[1] Rajasekaran, A., Sivakumar, V., Karthika, K., Preetha, J.P. and Anirami, T. (2010) Design and Evaluation of Polymeric Controlled Release Natamycin Ocular Inserts. Kathmandu University Journal of Science, Engineering and Technology, 6, 108-115. http://dx.doi.org/10.3126/kuset.v6i1.3318

[2] Sabitha, K., Sajeeth, C.I. and Santhi, K. (2012) Chitosan Nanoparticles: A Novel Vehicle for the Enhanced Ocular Delivery of Moxifloxacin HCl. Research Journal of Pharmaceutical, Biological and Chemical Sciences, 3, 534-548.

[3] Patel, H.A., Patel, J.K., Patel, K.N. and Patel, R.R. (2010) Ophthalmic Drug Delivery System: A Review. Der Pharmacia Lettre, 2, 100-115.

[4] Babizahayev, M.A. (2009) Current Ocular Drug Delivery Challenges For N-Acetylcarnosine: Novel Patented Routes and Modes Of Delivery, Design for Enhancement of Therapeutic Activity and Drug Delivery Relationships. Recent Patents on Drug Delivery \& Formulation, 3, 229-265. http://dx.doi.org/10.2174/187221109789105621

[5] Singh, V., Ahmad, R. and Heming, T. (2011) The Challenges of Ophthalmic Drug Delivery: A Review. International Journal of Drug Discovery, 3, 56-62. http://dx.doi.org/10.9735/0975-4423.3.1.56-62

[6] Sampath Kumar, K.P., Bhowmik, D., Harish, G., Duraivel, S. and Pragathi Kumar, B. (2012) Ocular Inserts: A Novel Controlled Drug Delivery System. The Pharma Innovation-Journal, 1, 1-16.

[7] Gupta, D. (2011) Review on Ocular Drug Delivery. Dehradun Institute of Technology, Dehradun.

[8] Rajasekaran, A., Arul Kumaran, K.S.G., Karthika, K. and Padma Preetha, J. (2010) A Comparative Review on Conventional and Advanced Ocular Drug Delivery Formulations. International Journal of PharmTech Research, 2, 668-674.

[9] Li, X.M., Cui, Y.D., Lloyd, A.W., Mikhalovsky, S.V., Sandeman, S.R., Howel, C.A. and Liao, L.W. (2008) Polymeric Hydrogels for Novel Contact Lens Based Ophthalmic Drug Delivery System: A Review. Contact Lens \& Anterior Eye, 31, 57-64. http://dx.doi.org/10.1016/j.clae.2007.09.002

[10] Weiner, A.L. and Gilger, B.C. (2010) Advancements in Ocular Drug Delivery. Veterinary Ophthalmology, 13, 395-406. http://dx.doi.org/10.1111/j.1463-5224.2010.00835.x

[11] Thakur, R.R. and Kashiv, M. (2011) Modern Delivery System for Ocular Drug Formulations: A Comparative Overview W.R.T. Conventional Dosage Forms-Review Paper. International Journal of Research in Pharmaceutical and Biomedical Sciences, 2, 8-18.

[12] Bisht, R. and Durgapal, S. (2011) Potential Advantages of Novel Intracorneal Drug Delivery System in Management of Fungal Keratitis-An Overview. International Journal of Pharmacy and Pharmaceutical Sciences, 3, 12-17.

[13] Giudice, G.L. and Galan, A. (2012) Basic Research and Clinical Application of Drug Delivery Systems for the Treatment of Age-Related Macular Degeneration. In: Ying, G.-S., Ed., Age Related Macular Degeneration-The Recent Advances in Basic Research and Clinical Care, InTech, Croatia, 99-120.

[14] Kalyanwat, R., Gupta, S., Songara, R.K. and Lokwani, P. (2011) Ocular Inserts: An Overview. International Journal of Pharmaceutical Research \& Development, 3, 141-148.

[15] Mohammad Zaki, A.J., Patil, S.K., Baviskar, D.T. and Jain, D.K. (2012) Implantable Drug Delivery System: A Review. International Journal of PharmTech Research, 4, 280-292.

[16] Yasukawa, T., Tabata, Y., Kimura, H. and Ogura, Y. (2011) Recent Advances in Intraocular Drug Delivery Systems. Recent Patents on Drug Delivery \& Formulation, 5, 1-10. http://dx.doi.org/10.2174/187221111794109529

[17] Malaekeh-Nilouei, B., Vahabzadeh, S.A. and Mohajeri, S.A. (2013) Preparation of a Molecularly Imprinted Soft Contact Lens as a New Ocular Drug Delivery System for Dorzolamide. Current Drug Delivery, 10, 279-285.

[18] Peng, C.C., Ben Shlomo, A., Mackay, E.O., Plummer, C.E. and Chauhan, A. (2012) Drug Delivery by Contact Lenses in Spontaneously Glaucomatous Dogs. Current Eye Research, 37, 204-211. http://dx.doi.org/10.3109/02713683.2011.630154

[19] Sindhumol, P.G. and Mohanachandran, P.S. (2011) Formulation and Evaluation of Sodium Cromoglycate Ophthalmic Inserts. International Journal of Drug Formulation \& Research, 2, 255-267.

[20] Gupta, S. and Gilhotra, R.M. (2011) Enhancement of Antiglaucoma Potential by Novel Ocular Drug Delivery System. 
International Journal of Pharmacy and Pharmaceutical Sciences, 3, 55-58.

[21] Shanmugam, S., Ramvignesh, T.R., Sundaramoorthy, K., Agyappan, T. and Vetrichelvan, T. (2011) Design and Evaluation of Novel Ophthalmic Delivery System of Acyclovir for Herpes Simplex Infection. Research Journal of Pharmaceutical, Biological and Chemical Sciences, 2, 802-814.

[22] Molokhia, S.A., Sant, H., Simonis, J., Bishop, C.J., Burr, R.M., Gale, B.K. and Ambati, B.K. (2010) The Capsule Drug Device: Novel Approach for Drug Delivery to the Eye. Vision Research, 50, 680-685. http://dx.doi.org/10.1016/j.visres.2009.10.013

[23] Ramkanth, S., Chetty, C.M., Alagusundaram, M., Angalaparameswari, S., Thiruvengadarajan, V.S. and Gnanaprakash, K. (2009) Design and Evaluation of Diclofenac Sodium Ocusert. International Journal of PharmTech Research, 1, 1219-1223.

[24] Kumar, A., Malviya, R. and Sharma, P.K. (2011) Recent Trends in Ocular Drug Delivery: A Short Review. European Journal of Scientific Research, 3, 86-92.

[25] Tiwari, A. and Shukla, R.K. (2010) Novel Ocular Drug Delivery Systems: An Overview. Journal of Chemical and Pharmaceutical Research, 2, 348-355.

[26] Mythri, G., Kavitha, K., Kumar, M.R. and Singh, S.J. (2011) Novel Mucoadhesive Polymer: A Review. Journal of Applied Pharmaceutical Science, 1, 37-42.

[27] Talegaonkar, S., Azeem, A., Ahmad, F.J., Khar, R.K., Pathan, S.A. and Khan, Z.I. (2008) Microemulsions: A Novel Approach to Enhanced Drug Delivery. Recent Patents on Drug Delivery \& Formulation, 2, 238-257. http://dx.doi.org/10.2174/187221108786241679

[28] Alagusundaram, M., Madhu, S.C.C., Umashankari, K., Badarinath, A.V., Lavanya, C. and Ramkanth, S. (2009) Microspheres as a Novel Drug Delivery System-A Review. International Journal of ChemTech Research, 1, 526-534.

[29] Katteboinaa, S., Chandrasekhar, P. and Balaji, S. (2009) Drug Nanocrystals: A Novel Formulation Approach to Poorly Soluble Drugs. International Journal of PharmTech Research, 1, 682-694.

[30] Hari, B.N.V., Kalaimagal, K., Porkodi, R., Gajula, P.K. and Ajay, J.Y. (2012) Dendrimer: Globular Nanostructured Materials for Drug Delivery. International Journal of ChemTech Research, 4, 432-451.

[31] Han, S., Shen, J., Gan, Y., Geng, H., Zhang, X., Zhu, C. and Gan, L. (2010) Novel Vehicle Based on Cubosomes for Ophthalmic Delivery of Flurbiprofen with Low Irritancy and High Bioavailability. Acta Pharmacologica Sinica, 31, 990-998. http://dx.doi.org/10.1038/aps.2010.98

[32] Nikam, V.K., Kotade, K.B., Gaware, V.M., Dolas, R.T., Dhamak, K.B., Somwanshi, S.B., et al. (2011) Iontophoresis in Drug Delivery: History and Application. Pharmacologyonline, 3, 543-561.

[33] Vodithala, S., Khatry, S., Shastri, N. and Sadanandam, M. (2010) Formulation and Evaluation of Ion Activated Ocular Gels of Detorolac Tromethamine. International Journal of Current Pharmaceutical Research, 2, 33-38.

[34] Rathore, K.S. (2010) In Situ Gelling Ophthalmic Drug Delivery System: An Overview. International Journal of Pharmacy and Pharmaceutical Sciences, 2, 30-34.

[35] Kumar, L., Singh, R.P., Gupta, S. and Kumar, D. (2011) In Situ Gel: A Novel System for Ocular Drug Delivery. International Journal of Pharmaceutical Sciences Review and Research, 9, 83-91.

[36] Champalal, K.D. and Poddar Sushilkumar, S. (2012) Current Status of Ophthalmic In-Situ Forming Hydrogel. International Journal of Pharmacy and Biological Sciences, 3, 372-388.

[37] Hiremath, S.S.P., Dasankoppa, F.S., Nadaf, A., Jamakandi, V.G., Mulla, J.S., Sreenivas, S.A., Sholapur, H.N., Aezazahmed and Nanjundaswamy, N.G. (2008) Formulation and Evaluation of a Novel in Situ Gum Based Ophthalmic Drug Delivery System of Linezolid. Scientia Pharmaceutica, 76, 515-532. http://dx.doi.org/10.3797/scipharm.0803-17

[38] Varshoaz, J., Tabbakhian, M. and Salmani, Z. (2008) Designing of a Thermosensitive Chitosan/Poloxamer in Situ Gel for Ocular Delivery of Ciprofloxacin. The Open Drug Delivery Journal, 2, 61-70. http://dx.doi.org/10.2174/1874126600802010061

[39] Ramaa, C.S., Mohan, R., Mundada, A.S. and Kadam, V.J. (2008) Advances in Contemporary Research. Retrometabolism Based Drug Targeting-Soft Drug Approach. Indian Journal of Chemistry, 47B, 721-723.

[40] Allen, L.V., Popwich, N.G. and Ansel, H.C. (2005) Ansel’s Pharmaceutical Dosage Forms and Drug Delivery Systems. 8th Edition, Lippincot Williams \& Wilkins, Philadelphia, 652-662.

[41] Hughes, P.M., Olejnik, O., Chang-Lin, J.E. and Wilson, C.G. (2005) Topical and Systemic Drug Delivery to the Posterior Segments. Advanced Drug Delivery Reviews, 57, 2010-2032. http://dx.doi.org/10.1016/j.addr.2005.09.004 